\title{
Política: um negócio de família?
}

\author{
Ana Crhistina Vanali ${ }^{1}$
}

O dossiê "A fabricação da hereditariedade na política" publicado em dezembro de 2016 na revista francesa Critique Internationale, organizado pelos professores Marie Brossier ${ }^{2}$ e Gilles Dorronsoro, pretende demonstrar as lógicas originais de produção da família como um lugar privilegiado de atuação da política, quer em termos de enunciação, representações ou práticas. Os artigos apresentam contribuições originais baseadas em evidências empíricas de diferentes locais do mundo. Essas contribuições também podem desenvolver uma abordagem mais reflexiva das dificuldades de acesso e coleta de material empírico no que toca a intimidade e privacidade (quando se fala em família), bem como uma abordagem metodológica sobre as ferramentas originais que os autores mobilizaram ou criaram para processar e analisar seus dados.

Como explicar o uso feito pelas sociedades democráticas de um vocabulário político que funciona sobre as bases de alusões à família como princípio de realidade social? Atualizadas pela mídia, essas alusões (afilhado político, os pais do partido, herança partidária, herdeiro político...) oferecem uma visão esparsa de significação da democracia e revelam a existência possível de uma relação entre duas esferas teoricamente inconciliáveis, onde uma se realiza mascarando a outra: as ideias de democracia, partido moderno e eleições dissimulando os sinais de família, isto é, do mundo social no político.

Além da ideia de um "caminho eleitoral" em direção à democracia ${ }^{3}$ e das mudanças institucionais implementadas desde a década de 1900, podemos ver que as lógicas familiares no acesso a posições e

\footnotetext{
${ }^{1}$ Doutora em Sociologia pela Universidade Federal do Paraná (UFPR). Pesquisadora do Núcleo de Estudos Paranaenses (NEP-UFPR). E-mail: anacvanali@yahoo.com.br

2 BROSSIER, Marie. Quand la mobilisation produit de l'institution : Pratiques de la famille et organisations religieuses au Sénégal. Tese de doutorado defendida em 2010 sob a orientação de Gilles Dorronsoro.

Esta tese explora o processo de produção da instituição através de mobilizações coletivas, articulando o corpus da sociologia das mobilizações e instituições. Com base em uma pesquisa de campo realizada no Senegal, é desenvolvido um estudo comparativo sobre a produção de casamentos e famílias em três organizações muçulmanas e cristãs sócio religiosas. A análise mostra que a instituição da família é o resultado de um esforço de construção por parte de atores que não são necessariamente estatais ou legais, mas que fazem parte de organizações pertencentes ao espaço social e religioso. Ao explorar a formação de uma matriz familiar de compromisso político, a pesquisa mostra como a produção de instituições familiares dentro desses grupos, diferenciando-se do modelo praticado na sociedade, constitui uma modalidade de politização sem precedentes formulada pelo envolvimento militante na esfera doméstica e pública.
}

${ }^{3}$ Consultar LINDENBERG, Staffan I. Democracy and Elections in Africa. Johns Hopkins University Press, 2006. 
recursos de poder são sempre resignificadas e permanecem no centro das trajetórias sócio históricas do Estado e nos modos de transferência de poder nas sociedades africanas ${ }^{4}$ e em outras sociedades. Brossier e Dorronsoro em seu artigo $^{5}$ demonstram que elas continuam a alimentar as relações de lealdade e fidelidades políticas, bem como a renovação do pessoal político. É esta questão que o dossiê aborda, questionando a permanência do peso da família e do parentesco em um contexto em que os sistemas de acumulação e redistribuição são enfraquecidos pela escassez de acesso aos recursos seguindo ajustes estruturais e as reformas neoliberais que os acompanharam desde a década de 1980.

Seguindo as propostas de diferentes abordagens disciplinares (história, antropologia, sociologia, ciência política), o dossiê propõe uma releitura das relações entre família e política e estuda a família como um lugar da política. Para isso, duas dimensões podem ser mobilizadas nas abordagens disciplinares:

1. a que considera a família e o parentesco como produtor de ordem social e da política (Tocqueville, Durkheim, Goody, Evans-Pritchard \& Fortes, Lonsdale, Dahou)

2. a que está em torno da ideia uma homologia de estruturas existentes entre a esfera familiar e a esfera política (Bourdieu).

Por outro lado, trata-se de abrir a discussão sobre uma "política de afetos". Parece impossível ficar satisfeito com a compreensão da política em termos de racionalidade desprovida de afetos, paixões e emoções ${ }^{6}$. Ao entrar, através de uma "política dos afetos", nas relações entre família e política, propõe-se restaurar a "fábrica emocional" e a "retórica afetiva" da política7. Quais são os registros mobilizados pelos líderes no jogo político e como eles são percebidos pelos cidadãos nas arenas políticas, eleitorais e partidárias? E no espaço público? Esta "política do afeto" também permitirá trabalhar em conjunto nas abordagens de "topo" (instituições políticas e elites) e "de baixo para cima" (estudo dos modos populares de ação política). Isso mostrará, por um lado, como o universo político é dominado por uma "linguagem de

\footnotetext{
${ }^{4}$ BAYART, Jean-François. L'état en Afrique: la politique du ventre. Paris: Fayard, 1989.

BAYART, Jean-François et all. The Criminalization of the State in Africa. Indiana University Press, 1997.

DALOZ, Laurent. Mentor: Guiding the Journey of Adult Learners. Wiley, 1999.

CAROTHERS, Thomas. The End of the Transition Paradigm. In : Jouirnal of democracy, v.13, n.1, p.5-21.

FOUCHER, Michel. Obsessão por Fronteiras. TSão Paulo: Radical Livros, 2009.
}

5 Texto original "Le paradoxe de la transmission familiale du pouvoir», Critique internationale, vol. 73, № 4, 2016, p.9-17. Disponível em https://www.cairn.info/revue-critique-internationale-2016-4-page-9.htm. Acesso 25.outubro.2017.

${ }^{6}$ BRAUD, Philippe. Sociologie politique. 3e éd. Paris: L.G.D.J., 1996.

BACOT, Paul «Philippe Braud, Sociologie politique», Mots. Les langages du politique 84, 2007.

TRAINI, Christophe (org.).Emotions... mobilisation! Mobilisation!, Paris: Presses de Sciences Po, 2009.

7 PERRINEAU, Pascal. La présence perturbatrice du Front national aux élections municipales. Paris : cevipof, 2014.

MARCHAL, Roland e MESSIANT, Christine (rogs). Les chemins da la guere et de la paix: Fins de conflits en Afrique orientale et australe. Paris: Karthala, 1997. 
sedução"8 que mobiliza e manipula os registros emocionais da família e do parentesco: até que ponto a rotinização de seus usos no discurso político dominante pode constituir uma maneira de ocultar as práticas de apropriação e a personalização do poder bem documentado na literatura?

A "política dos afetos" permitirá ver como o investimento desses registros pelos cidadãos (apropriação, rejeição ou reinvenção) alimenta os imaginários políticos coletivos e individuais do poder, ao mesmo tempo que constituem as origens da ação ${ }^{9}$. É, portanto, uma questão de reinvestir na discussão da relação entre o ponto de vista do doméstico e do privado, detalhando a historicidade das práticas de aliança, sedução, sexualidade, violência, adultério, procriação, paternidade que moldam as práticas políticas $^{10}$

Os diferentes artigos do dossiê nos fornecem contribuições que podem ser incluídas em três eixos que permanecem abertos e conectados:

1. A família como matriz de organização de poder cujo foco está nos quadros cognitivos e emocionais que moldam os imaginários políticos. Retorna-se a historicidade das "estruturas de significado"11 que nutrem o processo de naturalização e invenção da família como modelo de organização sócio-política, procurando ver como a formação da nação (Senegal, por exemplo) ou a do Estado (o Quênia, por exemplo) dependem do modelo, mesmo da instituição da própria família. O processo de produção de analogias entre o espaço político e familiar pode esclarecer os direitos ou deveres que vinculam as elites e os cidadãos no caminho de responsabilidades ou lealdades; relações entre pais e filhos ou os mais novos com os idosos, mobilizando a metáfora do corpo e a retórica orgânica para legitimar a dominação. Portanto, é necessário ir além de uma visão da família como uma instituição uniforme no tempo e no espaço.

2. O uso do parentesco e da hereditariedade como recurso na competição política questiona a ideia de que a transmissão do poder político dentro da mesma família parece ser favorecida ${ }^{12}$. Com base no

\footnotetext{
8 BRAUD, Philippe. Sociologie politique. 3e éd. Paris: L.G.D.J., 1996.

${ }^{9}$ MARCUS, Geroge E. Le citoyen sentimental. Émotions et politique en démocratie. Paris: Presses Science Po, 2008. BALLET, Marion. Peur, Espoir, Compassion, Indignation. L’appel aux émotions dans les campagnes présidentielles (1981-2007). Paris: Dalloz, 2012

10 NYAMJOH, Francis. Africa's Media: Between Professional Ethics and Cultural Belonging. Windhoek: Fesmedia Africa, FriedrichEbert-Stiftung2009.

COLE, Jennifer e THOMAS, Lynn M. (orgs). Love in Africa. Halftones, 2009.

STOLER, Ann Laura. Colonial Archives and the Arts of Governance. IN : Archival Science 2: 87-109, 2002.

${ }^{11}$ GEERTZ, Clifford. A interpretação das culturas. RJ: LTC, 1989.

12 MORGAN, Lewis. A sociedade antiga. RJ: Zahar, 2014.

ELIAS, Norbert. La dynamique de l’Occident. Paris: Agora, 2003.
} 
trabalho de "parentesco prático" ${ }^{13}$ se entende os contornos dos membros da família e dos parentes ${ }^{14}$. Vale refletir sobre os modos de socialização familiar de duas perspectivas: por um lado, o parentesco como modo de seleção e regulamentação dos $\operatorname{candidatos}^{15}$ e, por outro lado, a família como espaço para aquisição de capital e herança ${ }^{16}$. Todos os membros de uma família socializada na política não estão determinados a ter acesso aos mandatos políticos: é por isso que se analisa ${ }^{17}$ os métodos de preparação e a seleção de candidatos "elegíveis" para a entrada na competição política e o acesso ao mandato político. Procura-se ver como as redes de parentesco são organizadas em diferentes escalas (locais, regionais, nacionais, e mesmo internacionais) quando estão ligadas a redes políticas através da circulação de atores e alianças. O prestígio do patrônímico e os métodos de transmissão (reticularidade) devem ser observados sob o ângulo de sua territorialidade e a legitimidade conferida pela proximidade. Este eixo propõe, portanto, uma abordagem alternativa às visões funcionais aplicadas aos sistemas clientelistas e sublinha a importância do estudo a nível local para entender como as alianças políticas e as lógicas do poder legitimativo, a nível nacional, dependem de alianças históricas e afetivas (especialmente matrimonial), o que determina as coalizões políticas mais que os interesses. Em particular, questiona-se o posicionamento das mulheres como mães, esposas e filhas nessas redes, particularmente a partir de uma análise da construção de gênero dos papéis sociais que terão que levar em conta a linhagem patrilinear e matrilinear e as lógicas de sucessão.

\section{A lógica da qualificação e desqualificação que estrutura o entrelaçamento da família e da política -} aqui interessa os "arranjos" constitucionais e a "encenação" institucional implementada pelos líderes políticos para estabelecer a circulação política dos membros de suas redes familiares, uma questão curiosamente negligenciada pelos estudos sobre a institucionalização do poder político na África ${ }^{18}$. Essas "qualificações legais" de nomeações, cooptações, compra de votos, manipulações de resultados eleitorais

\footnotetext{
13 WEBER, Max. A ética protestante e o espírito do capitalismo. 1ạ edição, 1905. Paris: Gallimard, 2003.

14 BROSSIER, Marie. Quand la mobilisation produit de l'institution : Pratiques de la famille et organisations religieuses au Sénégal, 2010. BONTE, P.; PORQUERES-GENE, E.; WILGAUX, J. (ORGS). L'argument de la filiation aux fondements des sociétés européennes et méditerranéennes. Paris : Éditions de la Maison des sciences de l’homme, 2011.
}

${ }^{15}$ ABELES, Marc. Anthropologie politique de la modernité. In: L'Homme, 1992, N.121, p. 15-30.

${ }^{16}$ BOURDIEU, Pierre. "Estratégias reprodutivas e modos de dominação". In: Métodos de Pesquisa Científica em Serviço Social. 105 (1), 1994.

DROZ, Yvan. Faire et défaire des affaires en famille. Paris: PUFC, 2015.

AUGUSTINS, Georges. Comment se perpétuer? Devenir des lignées et destins des patrimoines dans les paysanneries européennes. Nanterre: Société d'ethnologie, 1989.

${ }^{17}$ BOURDIEU, Pierre. Le sens pratique. Paris: Les Éditions de Minuit, 1980.

18 POSNER, Daniel e YOUNG, Daniel. The Institutionalization of Political Power in Africa. In : Journal of democracy, v.18, n.3, 2007, p. 126-140. 
permitem a manutenção do clã familiar biológico na arena política. Além disso, questiona-se a arena partidária para restaurar o papel de executivos e membros de partidos políticos que têm uma trajetória ascendente dentro do partido do candidato da família, o que lhes permitir continuar e garantir seu acesso recursos e posições de poder ${ }^{19}$. Podemos então confrontar as lógicas de qualificação - políticas familiares, institucionais, partidárias, faccionais, de mídia (visibilidade extrema) com as políticas de desqualificação lideradas em particular pelas mobilizações partidárias e sociais (mídia, sindicatos, associações, intelectuais). $\mathrm{Na}$ verdade, elas se opõem à formação de redes familiares e políticas, chegando às vezes até a sua judiciarização (julgamento por delito de enriquecimento ilícito, por exemplo). Nesse sentido, um estudo sobre a economia afetiva de confiança e desconfiança política coloca a questão do prazo eleitoral como crucial, uma vez que determina o "jogo" e o "impedimento" dessas redes familiares e políticas.

Com esse dossiê pretende-se restaurar a lógica original de produção da família como um lugar da política em termos de enunciação, representações ou práticas e incentivar a apresentação de contribuições originais baseadas em evidências empíricas. Os artigos questionam e apresentam a forma como as relações entre família e política são formadas em outras áreas e abrem a comparação entre os diferentes casos, enfatizando como o entrelaçamento da família e da política prevalece em muitas regiões, tanto na América do Norte como na América do Sul, na Europa, na Ásia e nos Estados árabes, ou na África, para abandonar os preconceitos sobre as sociedades percebidas como tendo famílias "arcaicas" ou políticas "exóticas".

${ }^{19}$ BROWNLEE, Jason. Authoritarianism in an age of democratization. Cambridge, 2007. 